\title{
Vasopressin for treatment of shock following aprotinin administration
}

\section{[Traitement à la vasopressine pour un choc suivant l'administration d'aprotinine]}

Stephan R. Williams MD PhD, ${ }^{*}$ André Y. Denault MD FrCPC, ${ }^{*}$ Michel Pellerin MD FrCSC, $\dagger$

Raymond Martineau MD FRCPC*

Purpose: To describe the utility of vasopressin in the treatment of acute distributive shock clinically compatible with the diagnosis of aprotinin anaphylaxis.

Clinical features: A 57-yr-old female patient underwent repeat cardiac surgery to treat prosthetic valve endocarditis. She had received aprotinin during her first surgery 60 days ago. Despite a negative test dose of iv aprotinin 20,000 KIU, when aprotinin loading was initiated during the repeat surgery, the patient developed bronchospasm and hypotension secondary to acute distributive shock. Bronchospasm responded to inhaled salbutamol and ipatropium. The hypotension was refractory to high doses of phenylephrine. Two doses of iv vasopressin $5 \cup$ reversed the vasodilation and reestablished normal blood pressure.

Conclusion: Vasopressin, in association with alpha-agonists, can reverse acute refractory distributive shock following aprotinin administration.

Objectif : Décrire l'utilité de la vasopressine dans le traitement du choc aigu vasoréactif compatible avec le diagnostic de réaction anaphylactique à l'aprotinine.

Éléments cliniques : Une femme de 57 ans a de nouveau subi une intervention cardiaque pour traiter une endocardite sur prothèse valvulaire. Elle avait reçu de l'aprotinine lors de la première opération, 60 jours avant. Malgré une dose-test négative de 20000 KIU d'aprotinine, administrée au début de la deuxième opération, un bronchospasme et de l'hypotension secondaires au choc aigu vasoréactif se sont développés. L'inhalation de salbutamol et d'ipratropium a été efficace contre le bronchospasme, mais de fortes doses de phényléphrine n'ont pu contrer l'hypotension. Deux doses de $5 \mathrm{U}$ de vasopressine ont renversé la vasodilatation et rétabli la tension artérielle normale.

Conclusion : La vasopressine, associée à des alpha-agonistes, peut renverser un choc vasoréactif aigu et résistant survenant après l'administration d'aprotinine.

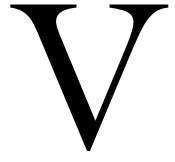

ASOPRESSIN has been recommended recently for the treatment of ventricular fibrillation, septic shock, ${ }^{1,2}$ and post-cardiopulmonary bypass distributive shock. ${ }^{3,4}$ In this case, we report the use of vasopressin in the treatment of acute distributive shock that occurred during the administration of aprotinin in a patient undergoing repeat cardiac surgery.

\section{Case report}

A 57 -yr-old, $56 \mathrm{~kg}$ woman with a history of rheumatic fever, type II diabetes mellitus, hypertension, and smoking underwent combined mechanical mitral (St. Jude $27 \mathrm{~mm}$ ) and aortic (St. Jude $19 \mathrm{~mm}$ ) valve replacements and left anterior descending coronary artery bypass with a left internal mammary artery graft. Her preoperative medications were metformin and hydrochlorothiazide. She had no known allergies. At the time of surgery, she received aprotinin (Bayer Vital, Leverkusen, Germany) as per the Hammersmith protocol. ${ }^{5}$ Her postoperative course was uneventful.

Two months later, the patient presented to the emergency room with chills and an altered level of consciousness. The patient was disoriented, stuporous, but arousable. She was tachycardic and had a temperature of $39^{\circ} \mathrm{C}$ without signs of meningismus or focal neurological findings. Laboratory tests revealed leukocytosis and acute azotemia with a serum creatinine of $221 \mu \mathrm{mol} \cdot \mathrm{L}^{-1}$. Cranial computerized tomography showed two small hypodensities compatible with embolic cerebral infarcts in the territories of each middle cerebral artery. Transesophageal echocardiography demonstrated a large vegetation on the mitral valve prosthesis, for which an emergency repeat cardiac surgery was scheduled. The patient was rehydrated, started on iv heparin, and treated with vancomycin,

From the Departments of Anesthesiology, ${ }^{*}$ and Heart Surgery, $\dagger$ Montreal Heart Institute, Montreal, Quebec, Canada.

Address correspondence to: Dr. André Y. Denault, Department of Anesthesiology, Montreal Heart Institute, 5000 Belanger Street East,

Montreal, Quebec HIT 1C8, Canada. Phone: 514-376-3330, ext. 3709; Fax: 514-376-8784; E-mail: denault@videotron.ca

Accepted for publication August 22, 2003.

Revision accepted October 3, 2003. 
rifampin and gentamicin. Eight of ten blood cultures were eventually positive for Staphylococcus epidermidis.

The patient was premedicated with morphine 7.5 $\mathrm{mg} i \mathrm{~m}$ and also received allopurinol $300 \mathrm{mg}$ po twice prior to the surgery. On arrival in the operating room, blood pressure (BP) measured from a radial arterial line was $110 / 70 \mathrm{mmHg}$, heart rate (HR) was 85 beats. $\mathrm{min}^{-1}$, and oxygen saturation was $100 \%$. General anesthesia was induced uneventfully with $i v$ midazolam $3 \mathrm{mg}$, sufentanil $80 \mu \mathrm{g}$, and pancuronium $10 \mathrm{mg}$. The trachea was intubated and mechanical ventilation with $100 \%$ oxygen was begun. Central venous lines and a pulmonary artery catheter were inserted. Anesthesia was maintained with an infusion of iv midazolam $0.04 \mathrm{mg} \cdot \mathrm{kg}^{-1} \cdot \mathrm{hr}^{-1}$, ketamine 0.5 $\mathrm{mg} \cdot \mathrm{kg}^{-1} \cdot \mathrm{hr}^{-1}$ and sufentanil $\mathrm{l} \mu \mathrm{g} \cdot \mathrm{kg}^{-1} \cdot \mathrm{hr}^{-1}$. As per the preoperative antibiotic administration schedule, iv vancomycin and gentamicin were slowly infused over $30 \mathrm{~min}$. During and following induction of anesthesia, the hemodynamic profile remained stable (Figure), with a $\mathrm{BP}$ of $110 / 55 \mathrm{mmHg}$, a pulmonary artery pressure (PAP) of $40 / 25 \mathrm{mmHg}$, a central venous pressure (CVP) of $13 \mathrm{mmHg}$, a cardiac index (CI) of $2.6 \mathrm{~L} \cdot \mathrm{min}^{-1} \cdot \mathrm{m}^{-2}$ and a systemic vascular resistance index (SVRI) of $24 \mathrm{mmHg} \cdot \mathrm{min} \cdot \mathrm{m}^{2} \cdot \mathrm{L}^{-1}$.

A test dose of aprotinin 20,000 KIU was infused intravenously over a period of ten minutes approximately 35 to $45 \mathrm{~min}$ after anesthetic induction. No adverse reaction was observed with the test dose; therefore, administration of the standard 2,000,000 KIU aprotinin loading dose was initiated. Approximately five minutes after the beginning of the loading dose, after $750,000 \mathrm{KIU}$ of aprotinin had been administered, the clinical diagnosis of an anaphylactic reaction to aprotinin was made when an increase in ventilatory pressures occurred simultaneously with severe abrupt hypotension and tachycardia. Chest auscultation revealed bilateral wheezing. Aprotinin infusion was immediately interrupted. Systolic arterial pressures remained at 50 to $60 \mathrm{mmHg}$ and the $\mathrm{HR}$ at 115 beats. $\mathrm{min}^{-1}$ despite volume infusion and repeated boluses $(100-400 \mu \mathrm{g})$ of $i v$ phenylephrine. At this time, cardiac index was measured at $3.8 \mathrm{~L} \cdot \mathrm{min}^{-1} \cdot \mathrm{m}^{-2}$; SVRI, PAP, and CVP had decreased to $10 \mathrm{mmHg} \cdot \mathrm{min} \cdot \mathrm{m}^{2} \cdot \mathrm{L}^{-1}, 26 / 18 \mathrm{mmHg}$, and 6 $\mathrm{mmHg}$ respectively. A phenylephrine infusion was begun and rapidly increased to $2 \mathrm{mg} \cdot \mathrm{min}^{-1}$. Concurrently, an $i v$ bolus of methylprednisolone 500 $\mathrm{mg}$ was administered. A total of $20 \mathrm{mg}$ of phenylephrine was administered over a ten-minute period, with minimal correction of the hypotension. An $i v$ bolus of vasopressin $5 \mathrm{U}$ was administered five minutes after the onset of the phenylephrine infusion. Systolic BP rapidly increased to $75 \mathrm{mmHg}$. A second bolus of iv vaso-

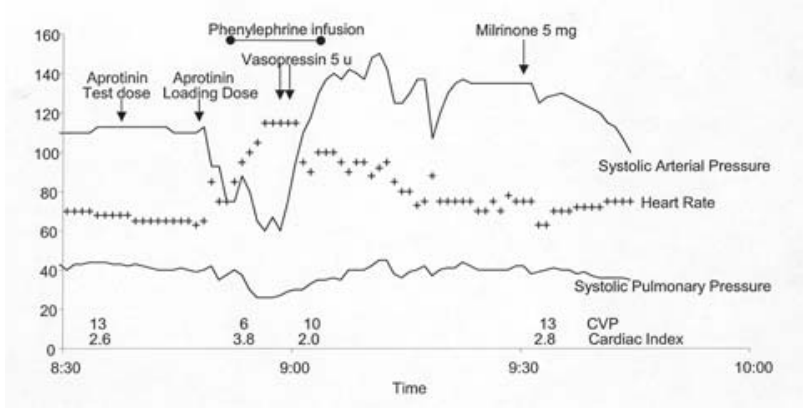

FIGURE Systolic arterial pressure (upper line), heart rate (crosses), systolic pulmonary arterial pressure (lower line), central venous pressure (CVP), and cardiac index, before, during, and after treatment of distributive shock following aprotinin administration. Time represents time of day. Blood pressures are reported in $\mathrm{mmHg}$, heart rate in beats per min, and the cardiac index in $\mathrm{L} \cdot \mathrm{min}^{-1} \cdot \mathrm{m}^{-2}$

pressin $5 \mathrm{U}$ was administered two minutes later following which $\mathrm{BP}$ increased to $140 / 80 \mathrm{mmHg}$ and remained stable thereafter. Phenylephrine infusion was rapidly discontinued. At this point, $\mathrm{PAP}$ was $35 / 23$ $\mathrm{mmHg}$, CVP $13 \mathrm{mmHg}$, CI $2.0 \mathrm{~L} \cdot \mathrm{min}^{-1} \cdot \mathrm{m}^{-2}$ and SVRI was elevated at $43 \mathrm{mmHg} \cdot \mathrm{min} \cdot \mathrm{m}^{2} \cdot \mathrm{L}^{-1}$. Ventilation pressures had returned to normal after endotracheal administration of $600 \mu \mathrm{g}$ of salbutamol and $80 \mu \mathrm{g}$ of ipratropium. Small doses of $i v$ nitroglycerin were given and $i v$ milrinone $5 \mathrm{mg}$ was infused over $20 \mathrm{~min}$ resulting in a pre-cardiopulmonary bypass (CPB) CI of 2.8 $\mathrm{L} \cdot \mathrm{min}^{-1} \cdot \mathrm{m}^{-2}$, BP of $100 / 50 \mathrm{mmHg}$, and a normal SVRI of $24 \mathrm{mmHg} \cdot \mathrm{min} \cdot \mathrm{m}^{2} \cdot \mathrm{L}^{-1}$. Antifibrinolytic therapy was achieved using epsilon-aminocaproic acid $10 \mathrm{~g} i v$ and $10 \mathrm{~g}$ in the pump priming solution.

Cardiopulmonary bypass was instituted without difficulty. During CPB, a mean arterial pressure between 50 to $80 \mathrm{mmHg}$ was maintained using only small intermittent doses of phenylephrine. At sternotomy, an intense mediastinal inflammation from the previous surgery was noted and the presence of a bivalvular endocarditis with massive vegetations was confirmed. The patient underwent a complex repair of the aortomitral junction with bovine pericardium and combined aortic (Carbomedics $21 \AA$, Austin, TX, USA), and mitral (St. Jude 27®, Minneapolis, MN, USA) valve replacement. Duration of CPB was five hours; the patient was successfully weaned from CPB with an $i v$ bolus of milrinone $5 \mathrm{mg}$ and an $i v$ infusion of norepinephrine 0.1 to $0.2 \mu \mathrm{g} \cdot \mathrm{kg}^{-1} \cdot \mathrm{min}^{-1}$. Perioperative trans- 
esophageal echocardiography demonstrated an excellent result with no valvular leak and normal left ventricular function. The infusion of norepinephrine was gradually tapered over $24 \mathrm{hr}$. The patient was extubated the next morning and her postoperative course was uneventful. She was discharged ten days after admission with home $i v$ antibiotic therapy.

\section{Discussion}

The use of aprotinin in cardiac surgery is increasing as it has been demonstrated to reduce perioperative blood loss. ${ }^{6,7}$ Aprotinin is a protein derived from bovine lung, and can induce an antigenic response in humans. ${ }^{8}$ Several cases of aprotinin anaphylaxis during cardiac surgery, including some in which the patient died despite aggressive treatment with epinephrine or norepinephrine, have been reported in the literature. ${ }^{8,9}$ The overall incidence of aprotinin-induced anaphylactic reactions in patients previously exposed to aprotinin has been reported to be $2.8 \%{ }^{8}$ A recent study suggested that reexposure to aprotinin within three months of initial exposure was associated with a relatively high incidence of anaphylactic reactions. ${ }^{10} \mathrm{In}$ this study, three of 17 patients incurred an adverse reaction to aprotinin when reexposed less than 90 days after initial exposure, while none of the 104 patients reexposed after 90 days had a reaction to aprotinin. Prophylaxis with $\mathrm{Hl}$ and $\mathrm{H} 2$ antagonists has been advocated before aprotinin reexposure in the hope of preventing or lessening the severity of aprotinin anaphylaxis, ${ }^{8}$ but the efficacy of this treatment has not been studied. Administration of an aprotinin test dose of 10,000 KIU has been advocated also upon reexposure. In other reported cases of aprotinin anaphylaxis, test doses of 10,000 to $50,000 \mathrm{KIU}$ did not produce any adverse hemodynamic effect. ${ }^{8,10}$ In our patient, aprotinin was readministered 55 days after initial exposure without prophylactic $\mathrm{H} 1$ and $\mathrm{H} 2$ blockade. Bronchospasm accompanied by distributive shock, consistent with a clinical diagnosis of anaphylaxis (biochemical markers of anaphylaxis were not measured), occurred despite the absence of an adverse reaction to the test dose.

Other medications administered within the hour prior to administration of aprotinin included midazolam, ketamine, sufentanil, pancuronium, vancomycin, and gentamicin. Midazolam, ketamine, and sufentanil infusions were continued throughout the surgery; thus, they were unlikely to be the cause of the hypotension. A reaction to pancuronium was unlikely, since it was re-administered as a 2 -mg bolus $30 \mathrm{~min}$ after a $0.05-\mathrm{mg}$ test dose without adverse effect. Vancomycin is known to cause hypotension when given rapidly; however, in this case it was administered over $30 \mathrm{~min}$, and several doses of vancomycin and gentamicin were administered postoperatively without hemodynamic compromise.

To our knowledge, this case is the first to report the use of vasopressin in the context of a clinical presentation consistent with anaphylaxis. Vasopressin acts as a non-adrenergic peripheral vasoconstrictor by direct stimulation of smooth muscle vasopressin ${ }_{1}$ receptors. It produces vasoconstriction in skin, skeletal muscle, intestine and fat, with relatively less constriction of coronary and renal vasculature, and causes a cerebral vasodilatation. ${ }^{11}$ Vasopressin has been integrated into the Advanced Cardiac Life Support resuscitation guidelines as an alternative pressor agent in the treatment of cardiac arrest. ${ }^{12}$ Vasopressin has been demonstrated to be effective in the management of catecholamine-resistant hypotension in the context of post-CPB vasodilatory shock $^{1,3,4}$ and septic shock. Our group has previously reported its effectiveness for treating catecholamine resistant hypotension during $\mathrm{CPB} .{ }^{13} \mathrm{~A}$ recent laboratory study demonstrated that the addition of vasopressin to epinephrine reverses histamine-induced vasodilation of human internal mammary arteries more completely than either agent alone, ${ }^{14}$ providing a physiological basis for the use of both types of pressor agents in the context of anaphylaxis.

In this case, vasopressin was administered before epinephrine because the vasodilation responsible for the hypotension was not corrected by large doses of an alpha-adrenergic agonist. Epinephrine would have been the next line of treatment had vasopressin not corrected the patient's hemodynamics. Administration of vasopressin contributed as a powerful alternative vasopressive mechanism. Also, in the context of septic endocarditis with valvular vegetations, it was hoped that the use of vasopressin would avoid a potentially deleterious epinephrine-induced tachycardia.

In conclusion, we report the case of a patient undergoing cardiac surgery, who presented with bronchospasm and refractory distributive shock following the administration of aprotinin 750,000 KIU. Bronchospasm was successfully treated by inhaled beta-2 agonists but hypotension was refractory to alpha-adrenergic stimulation with high doses of phenylephrine. Systemic vascular resistance, BP, and HR were normalized by a concomitant administration of vasopressin. Based on this report, we suggest that, in association with alpha-agonists, vasopressin may be an effective drug for the treatment of acute distributive shock compatible with the clinical diagnosis of anaphylaxis. The efficacy and safety of vasopressin associated with phenylephrine compared to epineph- 
rine for the treatment of anaphylaxis should be further confirmed through experimental studies followed, if appropriate, by a randomized controlled trial.

\section{References}

1 Dunser MW, Mayr AJ, Ulmer H, et al. The effects of vasopressin on systemic hemodynamics in catecholamine-resistant septic and postcardiotomy shock: a retrospective analysis. Anesth Analg 2001; 93: 7-13.

2 Tsuneyoshi I, Yamada H, Kakibana $\Upsilon$, Nakamura $M$, Nakano $\Upsilon$, Boyle WA 3rd. Hemodynamic and metabolic effects of low-dose vasopressin infusions in vasodilatory septic shock. Crit Care Med 2001; 29: 487-93.

3 Argenziano $M$, Chen JM, Choudhri AF, et al. Management of vasodilatory shock after cardiac surgery: identification of predisposing factors and use of a novel pressor agent. J Thorac Cardiovasc Surg 1998; 116: 973-80.

4 Morales DL, Gregg D, Helman DN, et al. Arginine vasopressin in the treatment of 50 patients with postcardiotomy vasodilatory shock. Ann Thorac Surg 2000; 69: 102-6.

5 Royston D, Bidstrup BP, Taylor KM, Sapsford RN. Effect of aprotinin on need for blood transfusion after repeat open-heart surgery. Lancet 1987; 2: 1289-91.

6 Lemmer JH Jr, Stanford W, Bonney SL, et al. Aprotinin for coronary bypass operations: efficacy, safety, and influence on early saphenous vein graft patency. A multicenter, randomized, double-blind, placebo-controlled study. J Thorac Cardiovasc Surg 1994; 107: 543-51.

7 Levy JH, Pifarre R, Schaff HV, et al. A multicenter, double-blind, placebo-controlled trial of aprotinin for reducing blood loss and the requirement for donorblood transfusion in patients undergoing repeat coronary artery bypass grafting. Circulation 1995; 92 : 2236-44.

8 Dietrich W, Spath P, Ebell A, Richter JA. Prevalence of anaphylactic reactions to aprotinin: analysis of two hundred forty-eight reexposures to aprotinin in heart operations. J Thorac Cardiovasc Surg 1997; 113: 194-201.

9 Diefenbach C, Abel M, Limpers B, et al. Fatal anaphylactic shock after aprotinin reexposure in cardiac surgery. Anesth Analg 1995; 80: 830-1.

10 Dietrich W, Spath P, Zublsdorf $M$, et al. Anaphylactic reactions to aprotinin reexposure in cardiac surgery: relation to antiaprotinin immunoglobulin G and E antibodies. Anesthesiology 2001; 95: 64-71.

11 Anonymous. Guidelines 2000 for Cardiopulmonary Resuscitation and Emergency Cardiovascular Care. Part 6: advanced cardiovascular life support: section 1 : introduction to ACLS 2000: overview of recommended changes in ACLS from the guidelines 2000 confer- ence. The American Heart Association in collaboration with the International Liaison Committee on Resuscitation. Circulation 2000; 102(8 Suppl): I86-9.

12 Lindner KH, Prengel AW, Brinkmann A, Strohmenger $H U$, Lindner IM, Lurie KG. Vasopressin administration in refractory cardiac arrest. Ann Intern Med 1996; 124: 1061-4.

13 Talbot MP, Tremblay I, Denault AY, Belisle S. Vasopressin for refractory hypotension during cardiopulmonary bypass. J Thorac Cardiovasc Surg 2000; 120: 401-2.

14 Tsuda A, Tanaka KA, Huraux C, et al. The in vitro reversal of histamine-induced vasodilation in the human internal mammary artery. Anesth Analg 2001; 93: 1453-9. 